\title{
Efficacy of dexmedetomidine premedication on attenuation of intraocular pressure changes after succinylcholine and endotracheal intubation
}

\author{
Sreenivas Reddy M. ${ }^{1}$, Pradeep Hosagoudar,", ${ }^{2,}$ Giridhar J. B. ${ }^{3}$, Y. V. Murali ${ }^{4}$, K. V. Srinivasan ${ }^{5}$ \\ ${ }^{1}$ Assistant Professor, ${ }^{2}$ Associate Professor, ${ }^{3}$ Senior Resident, ${ }^{4,5}$ Professor, Dept. of Anaesthesiology, P.E.S. Institute \\ of Medical Sciences and Research, Kuppam, Andhra Pradesh, India
}

*Corresponding Author:

Email: drpaddy82@gmail.com

Received: $06^{\text {th }}$ December, 2017

Accepted: $28^{\text {th }}$ December, 2017

\begin{abstract}
Introduction: Succinylcholine, is one of the most commonly used muscle relaxant for rapid sequence airway management. It increases the Intraocular pressure (IOP) which is deleterious in open globe injuries. We studied the effects of Inj. dexmedetomidine, a highly selective $\alpha_{2}$-adrenoceptor agonist, on IOP and hemodynamic responses to succinylcholine and tracheal intubation.

Materials and Methods: Sixty ASA I-II patients, scheduled for elective non-ophthalmic surgeries requiring general anesthesia were randomly premedicated by intravenous Inj. dexmedetomidine $0.4 \mu \mathrm{g} / \mathrm{kg}$ (Group-D) or saline (Group-S) (30 patients each group). Heart rate (HR), mean arterial pressure (MAP), and IOP (using Schiotz tonometer) were measured 10 minutes before and after the premedication, 30 seconds after succinylcholine and at 1, 5 and 10 minutes after intubation.

Results: Ten minutes after Inj. dexmedetomidine administration, there was marked decrease in IOP. After intubation there was a rise in IOP, however it remained below baseline IOP $(p=0.315)$ and remained low at $10^{\text {th }}$ minute after intubation $(p<0.001)$ which was statistically significant. In the control group, there was a significant rise in IOP following Inj. succinylcholine and intubation which remained above baseline IOP even at $10^{\text {th }}$ minute after intubation. HR, Systolic and diastolic blood pressure, and MAP markedly increased at 1 minute following intubation in the control group whereas in dexmedetomidine group, they remained below baseline $(\mathrm{p}<0.001)$.

Conclusions: Intravenous dexmedetomidine at a dose of $0.4 \mu \mathrm{g} / \mathrm{kg}$ can be used for attenuation of rise in IOP associated with succinylcholine and tracheal intubation in patients with open globe injuries.
\end{abstract}

Keywords: Dexmedetomidine, Eye, Intraocular pressure, Rapid sequence intubation, Succinylcholine.

\section{Introduction}

Emergency ophthalmic surgery pose a great challenge to the anesthesiologist. When the eye globe is open, any factor that increases the intraocular pressure (IOP) may possibly cause drainage of the aqueous humor or extrusion of the vitreous humor through the wound, which can permanently damage vision. These patients require rapid sequence induction and intubation without increasing the intraocular pressure. ${ }^{1}$

The intraocular pressure refers to the pressure exerted by intraocular fluids on the coats of the eyeball. The normal IOP ranges between 11-21 mmHg and IOP varies with the time of day, heart rate, blood pressure level and respiration. ${ }^{2}$ The major factors controlling IOP are the dynamic balance between aqueous humor production in the ciliary body and its elimination via the canal of Schlemm.

Succinylcholine, the most commonly used depolarizing muscle relaxant for rapid sequence airway management, increases the IOP by contraction of extraocular muscles. Succinylcholine stimulates the tonic system, thereby increasing the IOP. ${ }^{3}$ Laryngoscopy and tracheal intubation further aggravate the rise in IOP.

Dexmedetomidine is a highly selective $\alpha_{2}$ adrenergic agonist that has IOP-lowering properties. It is a more selective $\alpha_{2}$-agonist with a 1600 times greater selectivity for the $\alpha_{2}$ receptor compared with $\alpha_{1}$ receptor.
It causes dose dependent reductions in blood pressure and heart rate. Other beneficial effects of dexmedetomidine are anxiolysis, sedation, analgesia and sympatholysis with minimal respiratory depression. ${ }^{4}$ It has been observed that the rise of IOP with succinylcholine and intubation can be blunted with dexmedetomidine premedication. ${ }^{5}$

\section{Materials and Methods}

A prospective, randomized, controlled study was undertaken after obtaining Institutional Ethics Committee approval as well as informed consent from all patients. Sixty patients with ASA physical status grade I, II of either sex between 20 to 60 years of age scheduled for various elective non-ophthalmic surgeries necessitating general anesthesia were included in the study. Patients were randomly allocated by envelope method into 2 groups of 30 patients each- Group S $(n=30)$ received normal saline whereas patients in Group $\mathrm{D}(\mathrm{n}=30)$ received Inj.dexmedetomidine (i.v.) $0.4 \mu \mathrm{g} / \mathrm{kg}$ body weight. Patients with age $<20$ years and $>60$ years, hypertension, obesity with body mass index $>30$, ischemic heart disease (IHD), diabetes mellitus, raised IOP or any other ophthalmic disease, ASA physical status grade III \& IV, difficult airway, contraindication to dexmedetomidine or if the tracheal intubation could 
not be performed at the first attempt were all excluded from the study.

IOP was measured with Schiotz tonometer by an ophthalmologist who was unaware of the premedication drugs used. Topical 4\% lignocaine was instilled on the cornea 2 minutes prior to IOP measurement. Intraoperative monitoring included three-lead ECG, non-invasive blood pressure, plethysmography, capnography, temperature and neuromuscular monitoring.

Patients in Group-S received $50 \mathrm{ml}$ of normal saline i.v., whereas in Group-D Inj.dexmedetomidine $0.4 \mu \mathrm{g} / \mathrm{kg}$ diluted to $50 \mathrm{ml}$ using normal saline i.v. administered over 10 minutes using syringe infusion pump before induction of anesthesia. They were prepared in a doubleblind fashion by a team member who was not involved in data recording. The anesthesiologist responsible for providing anesthesia and recording heart rate and blood pressure, ophthalmologist who was recording intraocular pressure, and the patient were thus kept unaware of the content of the syringes.

All patients were premedicated with i.v. Inj.glycopyrrolate $0.2 \mathrm{mg}$ and Inj.fentanyl $2 \mu \mathrm{g} / \mathrm{kg}$. After preoxygenation for 5 minutes, anesthesia was induced with Inj.thiopentone $5 \mathrm{mg} / \mathrm{kg}$, neuromuscular blockade was achieved with Inj.succinylcholine $1.5 \mathrm{mg} / \mathrm{kg}$ to facilitate endotracheal intubation. Under direct laryngoscopy trachea was intubated with appropriate size endotracheal tube, placement was confirmed by auscultation and capnography. Anesthesia was maintained using Nitrous oxide 66\%, Oxygen 33\%, Isoflurane and Inj.vecuronium $0.05 \mathrm{mg} / \mathrm{kg}$ under mechanical ventilation. Appropriate intravenous fluids were used depending upon the surgical and the anesthetic needs. Inj.vecuronium and Inj.fentanyl were repeated as necessitated. At the end of surgery neuromuscular blockade was reversed using Inj.neostigmine $0.05 \mathrm{mg} / \mathrm{kg}$ and Inj.glycopyrrolate $0.01 \mathrm{mg} / \mathrm{kg}$ and extubated as per standard protocol.

The following parameters were recorded in both the groups: intraocular pressure (IOP), heart rate (HR), systolic blood pressure (SBP), diastolic blood pressure (DBP), mean arterial pressure (MAP) using GE - DatexOhmeda Anesthesia Monitor. IOP was measured using Schiotz indentation tonometer. The above parameters were recorded at the following time points:

1. $\mathrm{T}_{1}$ : 10 minutes before the study drug is injected (baseline).

2. $\mathrm{T}_{2}: 10$ minutes after the administration of study drug.

3. $\mathrm{T}_{3}$ : Thirty seconds after succinylcholine is injected.

4. $\mathrm{T}_{4}$ : One minute after intubation

5. $\mathrm{T}_{5}$ : Five minutes after intubation

6. $\mathrm{T}_{6}$ : Ten minutes after intubation

Sedation was assessed using Ramsay sedation scale. Side effects like hypotension (fall in systolic blood pressure $>30 \%$ of baseline), ${ }^{5-7}$ bradycardia (heart rate $<45$ beats $/ \mathrm{min}),{ }^{6}$ post-operative nausea, vomiting and any other side effects were studied and treated appropriately.

\section{Statistical Analysis}

Descriptive and inferential statistical analysis has been carried out in the present study. Results on continuous measurements are presented on Mean \pm SD (Min-Max) and results on categorical measurements are presented in Number (\%). Significance is assessed at 5 $\%$ level of significance $(\mathrm{p}<0.05)$. The following assumptions on data were made - dependent variables should be normally distributed, samples drawn from the population should be random, cases of the samples should be independent.

Student $\mathrm{t}$ test (two tailed, independent) and Chisquare/ Fisher Exact test were used to find the significance of study parameters on continuous scale between two groups (Inter group analysis) on metric parameters and categorical scale between two or more groups respectively. Leven1s test for homogeneity of variance has been performed to assess the homogeneity of variance and $\mathrm{p} \leq 0.01$ was considered to be strongly significant.

\section{Results}

Both groups were comparable with regards to mean age, sex, weight and duration of surgery. The mean basal IOP, HR, SBP, DBP and MAP were comparable in both groups and there was no statistically significant difference (Table 1).

The mean basal IOP were comparable in both groups $(p=0.508)$, (Table 2$)$. Statistically significant fall in IOP was noted in Group-D, 10 minutes after study drug administration, 30 seconds after succinylcholine administration $(\mathrm{p}<0.001)$ compared to the control group. The increase in mean IOP was observed at 1, 5 and 10 minutes after intubation in Group-S which was statistically highly significant compared to mean IOP in group D ( $<<0.001)$, (Fig. 1).

The mean basal HR were comparable in both groups $(p=0.277)$, (Table 3). Statistical evaluation between the groups showed a highly significant fall in HR in GroupD 10 minutes after study drug administration and 30 seconds after succinylcholine administration $(p<0.001)$. mean HR increased after administration of succinylcholine and at $1^{\text {st }}, 5^{\text {th }}$ and $10^{\text {th }}$ minute after intubation in group $\mathrm{S}$ was statistically highly significant compared to mean HR in Group-D (p<0.001), (Fig. 2).

The mean basal MAP were comparable in both groups $(p=0.330)$, (Table 4). Statistically significant fall in MAP in Group-D was noted 10 minutes after study drug administration and 30 seconds after succinylcholine administration $(\mathrm{p}<0.001)$. The mean MAP increase observed at intubation and $1^{\text {st }}, 5^{\text {th }}$ and $10^{\text {th }}$ minute after intubation in Group-S was statistically highly significant compared to mean MAP in Group-D ( $\mathrm{p}<0.001)$, (Figure $-3)$. In Group-D, 3 patients developed hypotension and 
was managed conservatively however there was no incidence of bradycardia in both the groups.

In Group-S sedation score was $2.43 \pm 0.50$ and in Group-D the score was $2.47 \pm 0.51$ statistical evaluation no difference in the sedation score between the two groups ( $p>0.05)$. In group $S$, none of the patients had side effects like bradycardia and hypotension. In Group-D, 3 patients had hypotension which is statistically not significant $(\mathrm{p}=0.237)$.

\section{Discussion}

Patients with penetrating eye injury may present with full stomach. Goal of anesthesia in this scenario is to secure the airway by rapid sequence induction technique without increasing the IOP. Succinylcholine, the most commonly used muscle relaxant for rapid sequence airway management increases the IOP. ${ }^{7}$

Laryngoscopy and intubation are noxious stimuli and are associated with hemodynamic response in the form of laryngosympathetic stimulation, resulting in hypertension, tachycardia, $\operatorname{arrhythmias}^{8}$ and rise in IOP. ${ }^{5,9,10}$ This rise in IOP is transitory, variable and may not be significant in otherwise normal individuals. But in patients with open globe injuries of the eye it may be detrimental $^{1}$. Thus attenuation of increase in IOP and hemodynamic response to laryngoscopy and tracheal intubation, in patients undergoing ophthalmic surgeries or with raised IOP is warranted.

Various methods to attenuate the effects of succinylcholine and intubation on IOP include selftaming ${ }^{11}$, pretreatment with nondepolarizing neuromuscular blocking agents, ${ }^{12-14}$ lidocaine, ${ }^{15}$ narcotics, nifedipine. ${ }^{16}$ However, no modality is devoid of drawbacks and limitations.

$$
\alpha_{2} \text {-agonists like clonidine }{ }^{17} \text { and }
$$

dexmedetomidine $e^{5,7,9}$ have been used to attenuate the rise in IOP and response to intubation, and have been found to be effective compared to all the drugs mentioned above, without any of the side effects like respiratory depression or increased incidence of PONV. Clonidine being less potent $\left(\alpha_{1}: \alpha_{2}=1: 220\right)$ compared to dexmedetomidine $\left(\alpha_{1}: \alpha_{2}=1: 1620\right)$ in its agonism to $\alpha_{2}$ receptors ${ }^{18}$ may not be ideally suited for this purpose. Hence, dexmedetomidine may be better drug among $\alpha_{2}$ agonists for suppressing the rise in IOP and hemodynamic responses following administration of succinylcholine, laryngoscopy and intubation.

Various authors have employed i.v. dexmedetomidine for blunting rise in IOP after succinylcholine, laryngoscopy and intubation in different doses (Table 5). Since most authors ${ }^{5,7,9}$ observed, 0.4 to $0.6 \mu \mathrm{g} / \mathrm{kg}$ of Inj. dexmedetomidine to be effective in attenuating the rise in IOP following succinylcholine, laryngoscopy and intubation, $0.4 \mu \mathrm{g} / \mathrm{kg}$ dose was chosen in our study.

In our study, in the control group, after succinylcholine there was a rise in IOP by $1.06 \mathrm{~mm} \mathrm{Hg}$ above baseline which is statistically significant $(\mathrm{p}=0.018)$. After intubation there was statistically highly significant increase in IOP to 3.08 $\mathrm{mm} \mathrm{Hg}$ above baseline $(\mathrm{p}<0.001)$. Even at 10 minutes after intubation, the IOP remained above baseline and is statistically significant $(\mathrm{p}=0.039)$. Our present study correlates with the studies done by Jaakola et $\mathrm{al}^{9} \mathrm{Pal} \mathrm{CK}$ et $\mathrm{al}^{7}$ and Mowafi et $\mathrm{al}^{5}$ who also found a rise in IOP following succcinylcholine, laryngoscopy and intubation. After dexmedetomidine bolus, a decrease in IOP by $3.03 \mathrm{~mm} \mathrm{Hg}$ in Group-D was noted which is statistically highly significant $(\mathrm{p}<0.001)$ and remained below the baseline IOP (by $2.70 \mathrm{~mm} \mathrm{Hg}$ ) and is statistically highly significant $(p<0.001)$. One minute after intubation there was a rise in IOP which almost reached the baseline value and hence was not statistically significant compared to baseline IOP $(p=0.315)$. Even at 10 minutes after intubation, the IOP remained below baseline which is statistically highly significant $(p<0.001)$. Mowafi et $\mathrm{al}^{5}$ noted IOP in the dexmedetomidine group was lower than the baseline at all times, however immediately after intubation IOP reading was not significantly different from that at baseline, unlike that in the control group which correlates with our study. Pal CK et $\mathrm{al}^{7}$ also noted that IOP in the dexmedetomidine group after intubation was not significantly different from that at baseline, whereas in control group was above baseline and remained elevated even at 10 minutes after intubation. Jaakola et $\mathrm{al}^{9}$ observed $34 \%$ reduction in IOP after dexmedetomidine bolus dose whereas in our study there was $17 \%$ reduction in IOP. This is probably because Jaakola et al used $0.6 \mu \mathrm{g} / \mathrm{kg}$, whereas $0.4 \mu \mathrm{g} / \mathrm{kg}$ of Inj.dexmedetomidine was used in our study. Our present study correlates with the studies done by Jaakola et al, ${ }^{9}$ Mowafi et $\mathrm{al}^{5}$ and $\mathrm{Pal} \mathrm{CK}$ et $\mathrm{al}^{7}{ }^{7}$ that there is a reduction in IOP in dexmedetomidine group at various time intervals.

In Group-S, mean $\mathrm{HR}$ at baseline, after administration of saline and Inj.succinylcholine were similar. However, statistically significant increase in HR occurred at $1^{\text {st }}, 5^{\text {th }}$ and $10^{\text {th }}$ minutes after intubation $(\mathrm{p}<0.001)$, and high even at $10^{\text {th }}$ minute compared baseline. Similar findings were also noted by Aho et $\mathrm{al}^{21}$ (1991) and Basar et $\mathrm{al}^{22}$ in 2008. In Group-D, there was significant decrease in mean HR compared to baseline after administration of Inj. dexmedetomidine $(\mathrm{p}<0.001)$, remained below baseline at other intervals, including at the time of intubation $(\mathrm{p}<0.05)$ and at $1^{\text {st }}, 5^{\text {th }}$ and $10^{\text {th }}$ minutes after intubation $(\mathrm{p}<0.001)$. Mowafi et $\mathrm{al}^{5}$ noted a reduction in HR by $14 / \mathrm{min}$, Scheinin et $\mathrm{al}^{23}$ and Ferdi et $\mathrm{al}^{24}$ noted a reduction in $\mathrm{HR}$ by $10 / \mathrm{min}$ after dexmedetomidine bolus dose, which correlates with our study. Basar et $\mathrm{al}^{22}$ noted that following laryngoscopy and intubation HR increased by $10 / \mathrm{min}$ in control group and whereas it decreased by $8 / \mathrm{min}$ from baseline in dexmedetomidine group which is statistically highly significant. The authors have observed a statistically 
significant $(\mathrm{p}<0.05)$ obtundation of heart rate response to intubation which concurs with our study.

In Group-S, variation in MAP were not noticed till intubation compared to basal values $(p>0.05)$. However, in Group-D, there was a statistically significant fall in MAP following dexmedetomidine administration by 10 $\mathrm{mm} \mathrm{Hg}(\mathrm{p}<0.001)$. Ferdi et $\mathrm{al}^{24}$ found a decrease in MAP by $13 \mathrm{~mm} \mathrm{Hg}$ and $3 \mathrm{~mm} \mathrm{Hg}$ in dexmedetomidine and control group respectively, compared to basal value before induction which concurs with our study. Basar et $\mathrm{al}^{22}$ and Mowafi et $\mathrm{al}^{5}$ also noted a decrease in MAP by $7 \mathrm{~mm} \mathrm{Hg}$ in dexmedetomidine group which compares with our study.

MAP remained $7 \mathrm{~mm} \mathrm{Hg}$ below baseline unlike the increase in MAP seen in control group (by $18 \mathrm{~mm} \mathrm{Hg}$ above baseline) which is statistically highly significant $(\mathrm{p}<0.001)$. MAP remained below baseline even at $10^{\text {th }}$ minute after intubation in dexmedetomidine group which is statistically highly significant $(\mathrm{p}<0.001)$ compared to control group where MAP reached baseline after 10 minutes.

In group $\mathrm{S}$, mean sedation score immediately after extubation was 2.43 and 2.47 in dexmedetomidine group which is statistically not significant $(p=0.799)$. In dexmedetomidine group, 3 patients developed hypotension, which was 20 minutes after drug administration. None of these patients required vasopressors for correction of hypotension and was effectively managed by decreasing volatile anesthetic concentration and infusing intravenous fluids.

Table 1: Patient characteristics $(n=30$ each). Data are mean (range) or Mean \pm SD*

\begin{tabular}{|c|c|c|c|}
\hline Time & Group-S (n=30) & Group-D $(\mathbf{n}=\mathbf{3 0})$ & p-value \\
\hline Age (years) & $42.60(20-65)$ & $42.63(20-60)$ & $0.992(\mathrm{~ns})$ \\
\hline Sex (Male:Female) & $16: 14$ & $16: 14$ & $1.000(\mathrm{~ns})$ \\
\hline Weight (kgs) & $61.07 \pm 6.23$ & $63.37 \pm 8.17$ & $0.225(\mathrm{~ns})$ \\
\hline $\begin{array}{l}\text { Mean duration of } \\
\text { surgery (in minutes) }\end{array}$ & $119.00 \pm 36.33$ & $125.10 \pm 33.55$ & $0.502(\mathrm{~ns})$ \\
\hline
\end{tabular}

Abbreviations: ${ }^{*} \mathrm{SD}=$ standard deviation, $\mathrm{p}<0.05$ significant, $\mathrm{ns}=$ statistically not significant

Table 2: Intergroup comparison of mean intraocular pressure (IOP in $\mathbf{m m ~} \mathrm{Hg}$ ) changes in response to succinylcholine and intubation between control group and dexmedetomidine group

\begin{tabular}{|c|c|c|c|}
\hline Time & Group-S & Group-D & p-value \\
\hline T1 & $17.89 \pm 1.63$ & $17.56 \pm 2.14$ & $0.508(\mathrm{~ns})$ \\
\hline T2 & $17.55 \pm 1.75$ & $14.53 \pm 2.08$ & $<0.001(\mathrm{hs})$ \\
\hline T3 & $18.95 \pm 1.75$ & $14.86 \pm 2.25$ & $<0.001(\mathrm{hs})$ \\
\hline T4 & $20.97 \pm 1.39$ & $16.91 \pm 2.79$ & $<0.001(\mathrm{hs})$ \\
\hline T5 & $19.30 \pm 1.34$ & $15.99 \pm 2.43$ & $<0.001(\mathrm{hs})$ \\
\hline T6 & $18.78 \pm 1.65$ & $15.59 \pm 2.29$ & $<0.001(\mathrm{hs})$ \\
\hline
\end{tabular}

T-time intervals as mentioned in the Methods of study. ns= statistically not significant, hs=highly significant.

Table 3: Intergroup comparison of mean heart rate (bpm) changes in response to succinylcholine and intubation between control group and dexmedetomidine group.

\begin{tabular}{|c|c|c|c|}
\hline Time & Group-S & Group-D & p-value \\
\hline T1 & $83.30 \pm 5.04$ & $86.53 \pm 15.33$ & $0.277(\mathrm{~ns})$ \\
\hline T2 & $83.67 \pm 5.47$ & $71.37 \pm 11.90$ & $<0.001(\mathrm{hs})$ \\
\hline T3 & $92.40 \pm 7.55$ & $70.80 \pm 10.94$ & $<0.001(\mathrm{hs})$ \\
\hline T4 & $108.87 \pm 10.78$ & $79.07 \pm 12.65$ & $<0.001(\mathrm{hs})$ \\
\hline T5 & $91.17 \pm 4.53$ & $75.33 \pm 12.55$ & $<0.001(\mathrm{hs})$ \\
\hline T6 & $83.77 \pm 4.88$ & $72.97 \pm 11.40$ & $<0.001(\mathrm{hs})$ \\
\hline
\end{tabular}

T-time intervals as mentioned in the Methods of study. ns= statistically not significant, hs=highly significant.

Table 4: Intergroup comparison of mean arterial pressure changes (MAP in $\mathbf{m m ~} \mathbf{H g}$ ) in response to succinylcholine and intubation between control group and dexmedetomidine group.

\begin{tabular}{|c|c|c|c|}
\hline Time & Group-S & Group-D & p-value \\
\hline T1 & $95.87 \pm 6.32$ & $97.63 \pm 7.56$ & $0.330(\mathrm{~ns})$ \\
\hline T2 & $97.30 \pm 6.03$ & $82.00 \pm 7.33$ & $<0.001(\mathrm{hs})$ \\
\hline T3 & $98.80 \pm 6.36$ & $79.17 \pm 7.14$ & $<0.001(\mathrm{hs})$ \\
\hline T4 & $113.40 \pm 6.81$ & $90.73 \pm 6.83$ & $<0.001(\mathrm{hs})$ \\
\hline T5 & $102.83 \pm 6.30$ & $84.93 \pm 7.26$ & $<0.001(\mathrm{hs})$ \\
\hline T6 & $97.57 \pm 5.80$ & $82.03 \pm 6.42$ & $<0.001(\mathrm{hs})$ \\
\hline
\end{tabular}

T-time intervals as mentioned in the Methods of study. ns= statistically not significant, hs=highly significant. 
Table 5: Dosage of dexmedetomidine employed by various authors

\begin{tabular}{|l|l|l|}
\hline S. N. & Authors and year & Dose of dexmedetomidine employed \\
\hline 1 & $\begin{array}{l}\text { Jaakola et } \mathrm{al}^{9}- \\
1992\end{array}$ & $\begin{array}{l}0.6 \mu \mathrm{g} / \mathrm{kg} \text { body weight i.v. over } 1 \text { minute, } \\
\text { administered 10 minutes before induction of } \\
\text { anesthesia. }\end{array}$ \\
\hline 2 & Lee et $\mathrm{al}^{19}-2007$ & $\begin{array}{l}2.5 \mu \mathrm{g} / \mathrm{kg} / \mathrm{hr} \text { i.v. } 10 \mathrm{minutes} \text { before induction } \\
\text { followed by } 0.4 \mu \mathrm{g} / \mathrm{kg} / \mathrm{hr} \text { i.v. infusion. }\end{array}$ \\
\hline 3 & $\begin{array}{l}\text { Mowafi et } \mathrm{al}^{5}- \\
2008\end{array}$ & $\begin{array}{l}0.6 \mu \mathrm{g} / \mathrm{kg} \text { body weight in } 50 \mathrm{ml} \text { saline i.v. } 10 \\
\text { minutes before induction. }\end{array}$ \\
\hline 4 & Pal CK et al ${ }^{7}-2011$ & $\begin{array}{l}0.4 \mu \mathrm{g} / \mathrm{kg} \text { and } 0.6 \mu \mathrm{g} / \mathrm{kg} \text { body weight in } 10 \mathrm{ml} \\
\text { saline i.v. over } 10 \text { minutes before induction. }\end{array}$ \\
\hline 5 & $\begin{array}{l}\text { Xu lili et } \mathrm{al}^{20}- \\
2012\end{array}$ & $\begin{array}{l}\text { 0.5 } \mu \mathrm{g} / \mathrm{kg} \text { body weight i.v. } 10 \text { minutes before } \\
\text { Induction of anesthesia. }\end{array}$ \\
\hline
\end{tabular}

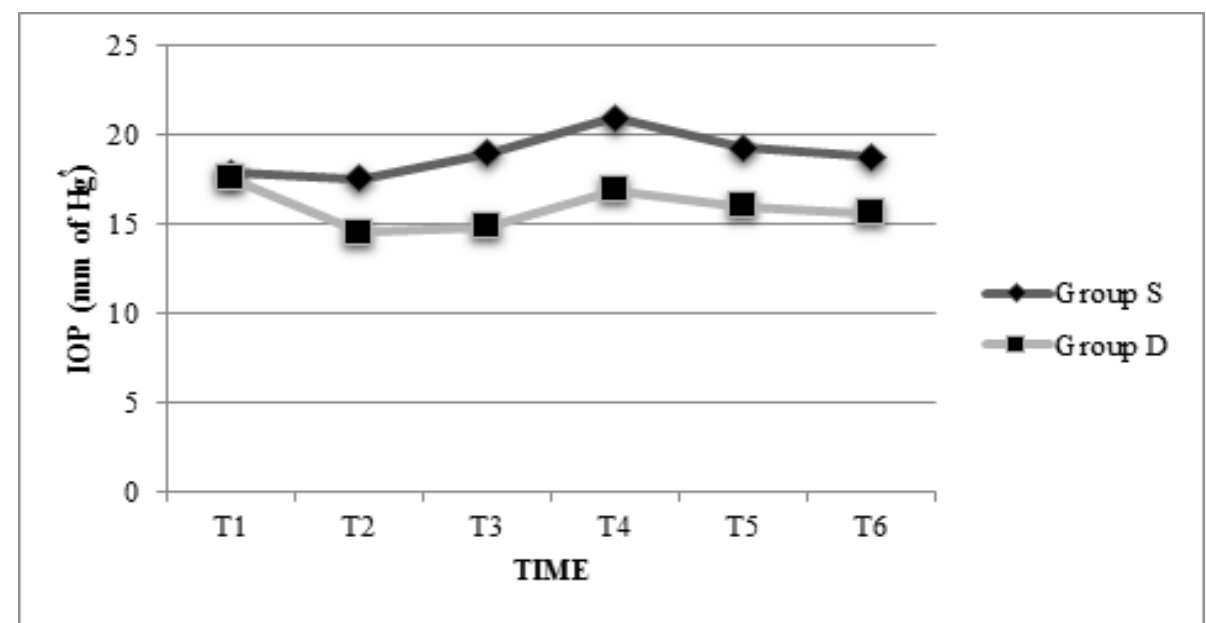

Fig. 1: Intergroup comparison of intraocular pressure (IOP) changes in response to succinylcholine and intubation between control group and dexmedetomidine group, ${ }^{*} \mathrm{~mm}$ of $\mathrm{Hg}=$ millimeters of mercury

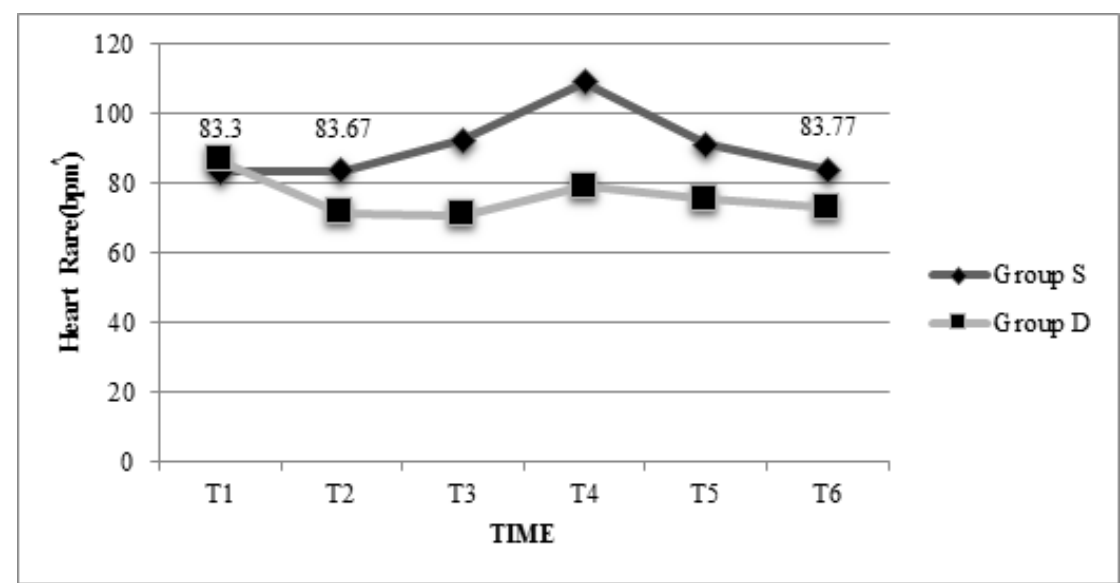

Fig. 2: Intergroup comparison of mean heart rate changes in response to succinylcholine and intubation between control group and dexmedetomidine group, 


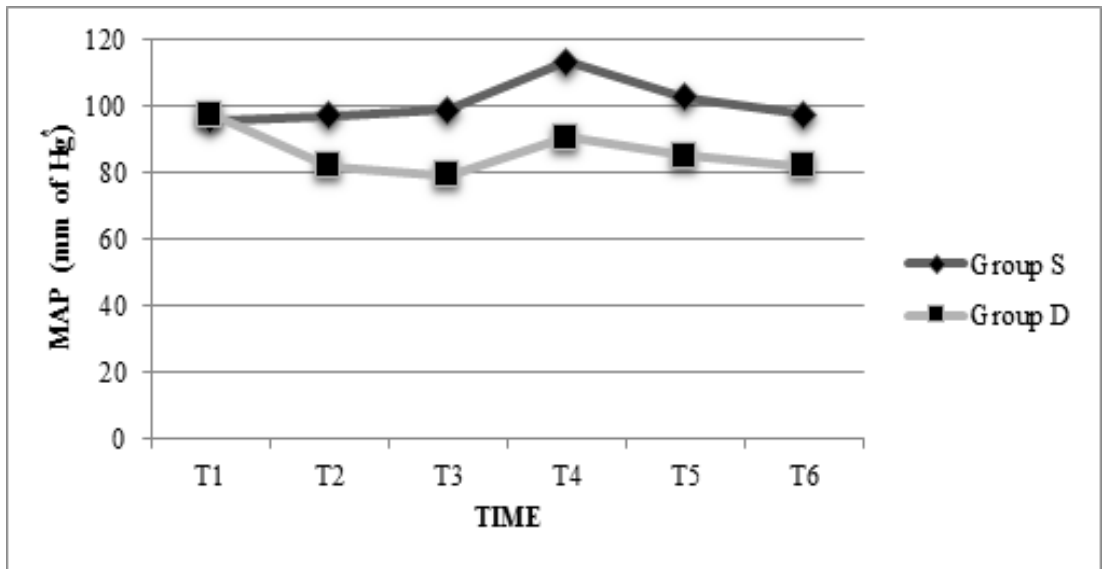

Fig. 3: Intergroup comparison of mean arterial pressure (MAP) changes in response to succinylcholine and intubation between control group and dexmedetomidine group, ${ }^{*} \mathrm{~mm}$ of $\mathrm{Hg}=$ millimeters of mercury

\section{Conclusion}

Dexmedetomidine $\quad 0.4 \mu \mathrm{g} / \mathrm{kg} \quad$ administered intravenously 10 minutes before induction of anesthesia, significantly obtunded the rise in intraocular pressure following administration of succinylcholine and endotracheal intubation. It also attenuated the hemodynamic response to laryngoscopy and endotracheal intubation without significant side effects. Hence, it would be beneficial in patients where rise in intraocular pressure can be detrimental.

\section{References}

1. Chidiac EJ, Raiskin AO. Succinylcholine and the open eye. Ophthalmology Clinics North America Journal 2006;19:279-85.

2. Jack J Kanski. Clinical Ophthalmology: sixth edition: 372-76.

3. Katz,R.L., and Eakins.K.E. The actions of neuromuscular blocking agents on EOM \& IOP. Proc Roy Soc Med 1969;62:1217-20.

4. Chen BS, Peng H, Wu SN. Dexmedetomidine, an $\alpha 2-$ adrenergic agonist, inhibits neuronal delayed - rectifier potassium current and sodium current. $\mathrm{Br} \mathrm{J}$ Anaesth 2009; 103:244-54.

5. Mowafi HA, Aldossary N, Ismail SA, Alqahtani J. Effect of dexmedetomidine premedication on the intraocular pressure changes after succinylcholine and intubation. $\mathrm{Br}$ J Anaesth 2008;100:485-9.

6. Lee YY, Wong SM, Hung CT. Dexmedetomidine infusion as a supplement to isoflurane anaesthesia for vitreoretinal surgery. Br J Anaesth 2007;98:477-83.

7. Pal CK, Ray M, Sen A, Hajra B, Mukherjee D, Ghanta AK. Changes in intraocular pressure following administration of suxamethonium and endotracheal intubation: influence of dexmedetomidine premedication. Indian Journal of Anaesthesia 2011;55(6):573-7.

8. King BD, Harris LC. Reflex circulatory responses to Direct laryngoscopy and Tracheal intubation performed during General anaesthesia. Anesthesiology 1951;12:55666.

9. Jaakola ML, Ali-Melkkila T, Kanto J, Kallio A, Scheinin $\mathrm{H}$, Scheinin M. Dexmedetomidine reduces intraocular pressure, intubation responses and anaesthetic requirements in patients undergoing ophthalmic surgery. Br JAnaesth 1992;68:570-5.
10. Ghai B, Sharma A, Akhtar S. Comparative evaluation of intraocular pressure changes subsequent to insertion of Laryngeal Mask Airway and endotracheal tube. Journal of Postgraduate Medicine 2001;47(3):181-4.

11. Verma RS. Self-taming of succinylcholine induced fasciculations and IOP. Anesthesiology 1979;50(3)245-7.

12. Sia RL, Rashkovsky OM. Org NC45 (vecuronium) and Intraocular pressure during anaesthesia. Acta Anaesth Scand 1981;25:219-21.

13. AI-Abrak MH, Samuel JR. Effects of general anaesthesia on the intraocular pressure in man. Comparison of tubocurarine and pancuronium in nitrous oxide and oxygen. Br J Ophthal 1974;58:806-10.

14. Chiu CL, Jaais F, Wang CY. Effect of rocuronium compared to succinylcholine on intraocular pressure during rapid sequence induction of anaesthesia. $\mathrm{Br} \mathrm{J}$ Anesth 1999;82(5):757-60.

15. Smith RB, Babinski M, Leano N. The effect of lidocaine on succinylcholine induced rise in intraocular pressure. Can Anaesth Soc J 1979;26:482-3.

16. Indu B, Batra YK, Puri GD, Singh H. Nifedipine attenuates the intraocular pressure response to intubation following succinylcholine. Can Journal Anaesth 1989;36(3):269.

17. Zahedi H, Nikooseresht M, and Rahro-Taban M. The effect of oral clonidine pretreatment on intraocular pressure and hemodynamic stability after succinylcholine injection and intubation in cataract surgery. Medical Journal of the Islamic Republic of Iran. 2007;21(2):1114.

18. Ralph Getler, Clieghton H Brown, Mitchel H, Silvius N. Dexmedetomidine: a novel sedative analgesic agent. Baylor University Medical Centre Proceedings 2001;14(1):13-21.

19. Lee YY, Wong SM, Hung CT. Dexmedetomidine infusion as a supplement to isoflurane anaesthesia for vitreoretinal surgery. Br J Anaesth 2007;98:477-83.

20. Xu Lili, Jianjum S, Haiyan Z. The application of dexmedetomidine in children undergoing vitreoretinal surgery. Journal of Anaesthesia 2012;26(4):556-61.

21. Aho M, Lehtnen AM, Erkola O, Scheinin H, Lehtinen A, Kallio A, et al. The effect of intravenously administered dexmedetomidine on perioperative haemodynamics and isoflurane requirements in patients undergoing abdominal hysterectomy. Anesthesiology 1991;74:997-1002.

22. Basar H, Akpinar S, Doganci N, Buyukkocak U, Kaymak $\mathrm{C}$, Sert O, et al. The effect of preanaesthetic, single dose dexmedetomidine on induction, haemodynamic and 
cardiovascular parameters. Journal of Clinical

Anaesthesia 2008;20:431-6.

23. Scheinin B, Lindgren L, Randell T, Scheinin H, Scheinin M. Dexmedetomidine attenuates sympathoadrenal responses to tracheal intubation and reduces the need for thiopentone and perioperative fentanyl. BrJ Anaesth 1992;68:126-31.

24. Menda F, Koner O, Sayin M, Ture H, Imer P, Aykac B. Dexmedetomidine as an adjunct to anesthetic induction to attenuate haemodynamic response to endotracheal intubation in patients undergoing fast-track CABG. Ann Card Anaesth 2010;13:16-21. 